\title{
Neutrophil-to-lymphocyte ratio is a predictor of renal dysfunction in diabetic patients
}

\author{
Taichi Akase \\ Ryuichi Kawamoto ( rykawamo@m.ehime-u.ac.jp ) \\ https://orcid.org/0000-0003-4674-0787 \\ Daisuke Ninomiya \\ Asuka Kikuchi \\ Teru Kumagi
}

\section{Research}

Keywords: neutrophil-to-lymphocyte ratio, estimated glomerular filtration rate, renal dysfunction

Posted Date: February 12th, 2020

DOI: https://doi.org/10.21203/rs.2.23384/v1

License: (c) (i) This work is licensed under a Creative Commons Attribution 4.0 International License. Read Full License 


\section{Abstract}

Background: Neutrophil-to-lymphocyte ratio (NLR) has been widely evaluated as a biomarker in various medical and surgical prognoses, but its usefulness in diabetic kidney disease is not yet known.

Methods: This prospective observational study included outpatients, comprised of 190 men aged $73 \pm 11$ (mean \pm standard deviation) years and 175 women aged $77 \pm 10$ years at baseline, from a rural hospital. We examined the relationship between baseline NLR calculated by analyzing the differential leukocyte counts in the complete blood count and the 1.5-year estimated glomerular filtration rate (eGFR) decline rate (i.e. 1.5-year eGFR - baseline eGFR) *100/baseline eGFR. Rapid eGFR decline rate was defined as a value $<\otimes 15 \%$.

Results: Multiple linear regression analysis using rapid eGFR decline rates as objective variables, adjusted for confounding factors as explanatory variables, showed that tertiles of $\operatorname{NLR}(\beta=0.120, p=0.018)$ as well as hemoglobinA1c, presence of antidiabetic medication, and urinary albumin excretion were significantly and independently associated with a rapid eGFR decline rate. The multivariate-adjusted odds ratios ( $95 \%$ confidence interval) of the $2^{\text {nd }}$ and $3^{\text {rd }}$ tertiles of baseline NLR for rapid eGFR decline rate were 3.94 (1.34-11.6) and 3.93 (1.2612.3), respectively. Multivariate-adjusted mean eGFR (95\% confidence interval) values after 1.5 years categorized by tertile of baseline NLR were: $1^{\text {st }}, 64.2(62.1-66.3) ; 2^{\text {nd }}, 60.5(58.5-62.6)$; and $3^{\text {rd }}, 59.1(57.0-61.2)$.

Conclusions: These results suggest that baseline NLR might be a useful biomarker for renal function decline in diabetic outpatients.

\section{Background}

Diabetic kidney disease (DKD) is the leading cause of chronic kidney disease (CKD) worldwide and one of the most serious complications of diabetes [1]. DKD still develops in approximately $30 \%$ of patients with type 1 diabetes and approximately $40 \%$ of patients with type 2 diabetes [2] [3] [4]. DKD is considered to begin from early glomerular hyperfiltration, followed by the development of microalbuminuria, macroalbuminuria, and then declined glomerular filtration rate (GFR), and ultimately, end stage renal disease (ESRD). Approximately 20 to $30 \%$ of the patients develop microalbuminuria after 15 years of having the disease and less than half develop real nephropathy [5]. Several pathophysiologic pathways, including risk factors (e.g. age, male gender, race, and family history), initiating factors (e.g. hyperglycemia, which is the most important), and perpetuating factors (e.g. obesity, hypertension, dyslipidemia, inflammatory cytokines, oxidative stress), are involved in the development of DKD [6]. Management of the modifiable risk factors might help in reducing its incidence soon.

Recently, many studies have identified new pathways involved in the onset and progression of DKD and have shown an important role of inflammation in the pathogenesis of DKD [7] [8]. Proposed inflammatory indices, such as C-reactive protein (CRP) levels, neutrophil-to-lymphocyte ratio (NLR), and platelet-to-lymphocyte ratio (PLR), have been considered useful indicators and cost-effective tests that can be easily measured in the laboratory. Among these indices, NLR in total white blood cell (WBC) counts has been studied in cardiac diseases and non-cardiac diseases (e.g. malignancies) as an inflammatory marker and predictor of the prognosis of diseases such as recurrence and mortality of cardiovascular disease (CVD) [9] [10] [11] [12] [13] [14], and surgical conditions [15] [16] [17]. NLR has recently emerged from among inflammatory parameters as a significant independent predictor of CVD complications in diabetic patients during a 4-year follow-up study [18]. In a cross-sectional study, the data suggested that NLR might be important as a potential factor for evaluating patients with a higher degree of 
albuminuria and decreased eGFR among diabetic outpatients [19]. However, the usefulness of NLR as a predictor of DKD has not been studied and its importance in nephrology has not yet been established.

Thus, the aim of this study was to examine the relationship between NLR, potential risk factors (such as age, gender, history of CVD, hypertension, hyperglycemia, lipids, serum uric acid [SUA]), and renal function by examining prospective data from diabetic outpatients.

\section{Methods}

\section{Subjects}

Participants were continuously recruited from diabetic outpatients that visited the medical department of Seiyo Municipal Nomura Hospital from April to June 2017 [19]. Those with an estimated glomerular filtration rate (eGFR) of $<30 \mathrm{ml} / \mathrm{min} / 1.73 \mathrm{~m}^{2}$ were excluded. Patients who had severe tissue damage, acute massive hemorrhage, acute poisoning, cancer, acute coronary artery disease, heart failure, active infection, or blood diseases affecting neutrophils and lymphocytes were also excluded. Patients with medications that may affect neutrophils and lymphocytes were also excluded. The study complies with the Declaration of Helsinki and was approved by the Ehime University Ethics Committee (IRB Approval Number: 1709006). Written informed consent was obtained from each subject.

\section{Evaluation of confounding factors}

All enrolled patients were interviewed and clinically examined at presentation. Their medical history, present conditions, smoking status, alcohol consumption, and medications (e.g. antihypertensives, antidyslipidemics, and antidiabetics) were obtained by interview using a structured questionnaire. Body mass index (BMI) is calculated as a person's weight in kilograms divided by height in meters squared. Systolic blood pressure (SBP) and diastolic blood pressure (DBP) were recorded using an automatic oscillometer at the right upper arm of patients while in a sedentary position. Smoking status was defined as the number of cigarette packs per day multiplied by the number of years smoked (pack-year), and the participants were classified as never smokers, past smokers, light smokers (<20 pack-year) or heavy smokers ( $\geq 20$ pack-year). Alcohol consumption was measured using the Japanese liquor unit, in which a unit corresponds to $22.9 \mathrm{~g}$ of ethanol, and the participants were classified as never drinkers, occasional drinkers ( $<1$ unit/day), daily light drinkers ( $<2$ units/day), or daily heavy drinkers ( $\geq 2$ units/day). Total cholesterol (T-C), high-density lipoprotein cholesterol (HDL-C), hemoglobin A1c (HbA1c), creatinine (Cr), SUA, and WBC count were measured during fasting. NLR was the ratio of neutrophil to lymphocyte. Non-HDL cholesterol (Non-HDL-C) was calculated by subtracting HDL-C from T-C. Urinary spot samples were collected after rest in the morning for analysis of urinary albumin and creatinine. Urinary albumin excretion (UAE) was expressed by the albumin: creatinine ratio $(\mathrm{mg} / \mathrm{g})$, and the participants were classified into the A1 stage (<30 mg/g Cr), A2 stage (30 to $300 \mathrm{mg} / \mathrm{g} \mathrm{Cr}$ ), or A3 stage ( $\geq 300 \mathrm{mg} / \mathrm{g} \mathrm{Cr}$ ). The eGFR was calculated using the CKD Epidemiology Collection (CKD-EPI) equations modified with a Japanese coefficient: Male, $\mathrm{Cr} \leq 0.9 \mathrm{mg} / \mathrm{dl}, 141 \times(\mathrm{Cr} / 0.9)^{-0.411} \times 0.993$ age $\times$ $0.813 ; \mathrm{Cr}>0.9 \mathrm{mg} / \mathrm{dl}, 141 \times(\mathrm{Cr} / 0.9)^{-1.209} \times 0.993$ age $\times 0.813 ;$ Female, $\mathrm{Cr} \leq 0.7 \mathrm{mg} / \mathrm{dl}, 144 \times(\mathrm{Cr} / 0.7)^{-0.329} \times 0.993$ age $\times 0.813 ; \mathrm{Cr}>0.7 \mathrm{mg} / \mathrm{dl}, 144 \times(\mathrm{Cr} / 0.7)^{-1.209} \times 0.993$ age $\times 0.813$ [20]. Moreover, past ischemic stroke, ischemic heart disease, and obstructive arteriosclerosis were defined as CVD.

\section{Outcomes}


The eGFR decline rate was calculated from the difference between the eGFR value after 1.5 years and that of the baseline year, divided by baseline eGFR (i.e. [1.5 year eGFR-baseline eGFR]*100/baseline eGFR). A rapid eGFR decline rate was defined as a 1.5-year eGFR decline rate of $<\bigotimes 15 \%$.

\section{Statistical analysis}

All continuous variables with normal distribution were presented as the mean \pm standard deviation (SD), and nonnormal variables (e.g. TG, HbA1c, and NLR) were reported as the median (interquartile range). In all analyses, parameters with non-normal distributions were used after log-transformation. Subjects were divided into three groups based on tertile of baseline NLR $\left(1^{\text {st }}, 0.65-1.56 ; 2^{\text {nd }}, 1.57-2.33 ; 3^{\text {rd }}, 2.34-15.3\right)$. Differences in means and prevalence between the three groups were examined by analysis of variance (ANOVA) for continuous data and a $\chi^{2}$ test for categorical data. Pearson's correlations were calculated in order to characterize the associations between baseline characteristics and rapid eGFR decline rate. Multiple logistic regression analysis was used to evaluate the contribution of each confounding factor, including NLR, to the rapid eGFR decline rate. Analysis of covariance (ANCOVA) was performed with the use of a general linear model approach to determine the association between baseline NLR and multivariate-adjusted eGFR after 1.5 years. In these analyses, eGFR values after 1.5 years were considered the dependent variables and the three ranges of NLR were considered the independent variables. Statistical analysis was performed using IBM SPSS Statistics software, version 21 (Statistical Package for Social Science Japan, Inc., Tokyo, Japan). A value of $p<0.05$ was considered significant.

\section{Results}

\section{Baseline characteristics of subjects categorized by tertile of baseline NLR}

Characteristics of the subjects categorized by tertile of baseline NLR are illustrated in Table 1. This prospective observational study included outpatients, comprised of 190 men aged $73 \pm 11$ years and 175 women aged $77 \pm 10$ years at baseline. Age was higher in correlation with increased tertile of NLR, but BMI, DBP, and eGFR were lower. There were no inter-group differences based on gender, period of diabetes, smoking status, daily alcohol consumption, CVD, SBP, presence of antihypertensive medication, HDL-C, Non-HDL-C, presence of antilipidemic medication, HbA1c, presence of antidiabetic medication, SUA, SUA-lowering medication, or UAE stage.

\section{5-year eGFR decline rate of subjects categorized by tertile of baseline NLR}

Fig. 1 shows the eGFR transition in subjects categorized by tertile of baseline NLR.

The change in mean eGFR during the 1.5 years of the $1^{\text {st }}$ NLR tertile was more gradual compared with the $2^{\text {nd }}$ and $3^{\text {rd }}$ NLR tertiles. As shown in Table 2, the $1^{\text {st }}$ NLR tertile had fewer patients (4.1\%) with a primary outcome (i.e. 1.5 year eGFR decline rate $<\otimes 15 \%)$ compared with the $2^{\text {nd }}$ and $3^{\text {rd }}$ NLR tertiles, which had more patients with primary outcomes (19.5\% and $17.4 \%$, respectively) with a significant $p$-value of 0.006 .

\section{Relationships between baseline confounding factorsand early eGFR decline rate}

Table 3 shows the simple relationship between baseline confounding factors and rapid eGFR decline rate. Pearson's correlation coefficient showed that tertile of NLR, age, SBP, presence of antihypertensive medication, HDL-C and UAE stage were significantly correlated with a rapid eGFR decline rate. Multiple linear regression 
analysis using rapid eGFR decline rate as an objective variable, adjusted for baseline confounding factors as explanatory variables, showed that tertile of NLR, age, non-HDL-C, and UAE stage was significantly and independently associated with a rapid eGFR decline rate.

\section{Non-adjusted and adjusted odds ratio $(95 \% \mathrm{Cl})$ of the tertiles of baseline NLR for the early 1.5 -year eGFR decline rate}

As shown in Table 4, the non-adjusted and multivariate-adjusted odds ratios (ORs) (95\% confidence interval [CI]) of the $1^{\text {st }}, 2^{\text {nd }}$, and $3^{\text {rd }}$ tertiles of baseline NLR for rapid eGFR decline rate were1, 5.62 (2.07-15.3), and 4.87 (1.77-13.4) and 1, 3.94 (1.34-11.6), and 3.93 (1.26-12.3), respectively.

\section{Non-adjusted and adjusted eGFR after 1.5 years of subjects categorized by tertile of baseline NLR}

The non-adjusted mean $(95 \% \mathrm{Cl})$ eGFR values after 1.5 years of the $1^{\text {st }}, 2^{\text {nd }}$, and 3 rd tertiles of baseline NLR were 65.5 (62.8-68.2) $\mathrm{mL} / \mathrm{min} / 1.73 \mathrm{~m}^{2}, 59.6$ (56.9-62.4), and 58.7 (55.9-61.4), respectively; the multivariate-adjusted mean values were 64.2 (62.1-66.3), 60.5 (58.5-62.6), and 59.1 (57.0-61.2), respectively. Both eGFR values after 1.5 years of the $2^{\text {nd }}$ and $3^{\text {rd }}$ tertiles of baseline NLR were significantly lower compared with those of the $1^{\text {st }}$ tertile (Table 5).

\section{Discussion}

In this prospective study of 365 diabetic outpatients, we determined the rate of decline in renal function as assessed by eGFR. Baseline NLR was assessed for its significance in the development of DKD, independently of potential confounding factors. The important finding of this study was that baseline NLR levels were found to be significantly associated with 1.5-year eGFR decline rate and future eGFR after 1.5 years among diabetic outpatients, even after adjusting for possible confounders such as gender, age, BMI, lifestyle, history of CVD, medication, blood pressure, lipids, glucose control, SUA, and UAE stage. Since NLR values are used extensively in the medical field, NLR may be used as a cost-effective predictor of inflammation. Finally, we demonstrated that threshold values for NLR determine early eGFR decline rate.

NLR has been reported as an inflammatory-based marker that is widely available, easy to obtain, and inexpensive to measure, providing values that can aid in the risk stratification of patients with various diseases [14] [18] [21] [22] [23]. In addition, NLR is very stable compared with absolute counts (such as total leukocyte, neutrophil, lymphocyte, monocyte, and platelet counts), which can be altered by various physical, physiological, and pathological factors [24]. Several recent studies have demonstrated possible associations between NLR and the development and acceleration of some diabetic complications such as diabetic retinopathy [25], nephropathy including UAE of 30-300 mg/g Cr or overt nephropathy [24] [26] [27] [28] [29] [30] [31], and neuropathy [32]. In a 3year follow-up study of 338 diabetic patients, NLR predicted worsening of renal function as a continuous decrease in GFR $>12 \mathrm{~mL} / \mathrm{min}$ with the final value being GFR $<60 \mathrm{~mL} / \mathrm{min}$ [24]. In 253 patients with type 2 diabetes, the NLR values of the patients with early-stage diabetic nephropathy were higher than those of patients without diabetic nephropathy $(p<0.001)$. NLR levels were positively correlated with diabetic nephropathy $(\mathrm{OR}, 2.09 ; 95 \% \mathrm{Cl}, 1.27-$ 3.43) [29]. Furthermore, baseline NLR was significantly and independently associated with increased 1.5-year eGFR decline rate and decreased eGFR after 1.5 years as a primary outcome. 
The mechanisms that lead to increased NLR in individuals with early stage DKD remain unknown. Diabetes is a chronic systemic disease. Many reports in the literature have suggested that various inflammatory responses play crucial roles in the pathogenesis and development of insulin resistance, which is one of the main causative factors for the etiology of type 2 diabetes [33]. Numerous studies have demonstrated that circulating biomarkers of these pathways such as tumor necrosis factor (TNF)-a, interleukin (IL)-6, CRP, vascular cellular adhesion molecule-1, interstitial cellular adhesion molecule-1, E-selectin, von Willebrand factor (endothelial dysfunction), plasminogen activator inhibitor-1, fibrinogen, and P-selectin (procoagulant state) may be associated with the development of diabetes. Some studies, particularly those on type 2 diabetes, have demonstrated that certain biomarkers could contribute to increased diabetic vasculopathies [34]. Inflammation in particular plays an essential role in the progression of DKD. Therefore, the number and percentage of WBC fractions recognized as novel biomarkers for systemic inflammation were strongly correlated with the development of DKD. In addition, many studies have demonstrated that NLR is positively associated with metabolic syndrome [35] and the prognosis of diseases such as acute coronary atherosclerosis [21] [23] [36], stroke [37], and cancer [22] [38], in which inflammation is significantly involved in their onset and progression.

However, some limitations could not be avoided. First, estimation of GFR using CKD tends to be less accurate in subjects with normal kidney function and CKD compared to inulin clearance. It is, however, more accurate than $\mathrm{Cr}$ or eGFR when the Modification of Diet in Renal Disease (MDRD) formula is used [20]. Second, baseline confounders and eGFR are based on a single assessment of blood, which can cause misclassification bias. Third, the failure to perform a renal biopsy cannot eliminate the potential impact of underlying diseases and medications on hypertension, diabetes, and dyslipidemia on NLR and renal dysfunction. However, renal diseases other than DKD and diseases that may affect NLR were eliminated as much as possible. Nevertheless, the demographics and referral source may limit generalization.

\section{Conclusions}

This study suggested that baseline NLR might be a surrogate marker of early eGFR decline rate in diabetic outpatients. The underlying mechanisms behind this relationship are completely unknown, and these factors seem to be independent of baseline confounding factors, such as age, gender, smoking status, alcohol consumption, history of CVD, hypertension, lipids, HbA1c, and SUA. Further studies are needed to evaluate whether baseline NLR is a useful marker to predict the incidence of early renal function decline.

\section{Declarations}

\section{Authors' contributions}

TA and RK participated in the design of the study, performed the statistical analysis and drafted the manuscript. TA, RK, DN, and AK contributed to the acquisition and interpretation of data. TA, RK, DN, and TK contributed to the conception and design of the statistical analysis. All authors read and approved the manuscript.

\section{Acknowledgements}

We would like to thank Uni-edit (https://uni-edit.net/) for editing and proofreading this manuscript.

\section{Competing interests}

The authors declare that they have no competing interests. 
Availability of data and materials

The data from this study can be acquired from the corresponding author upon reasonable request.

\section{Consent for publication}

Not applicable.

\section{Ethics approval and consent to participate}

This study conformed to the guidelines of the Declaration of Helsinki, and the study procedures were reviewed and approved by the medical research ethics committee of Ehime University Graduate School of Medicine. Each patient agreed to participate and signed the informed consent form.

\section{Funding}

This work was supported in part by a grant-in-aid from the Foundation for Development of Community (2019). No additional external funding was received for this study. The funders had no role in the study design, data collection and analysis, decision to publish, or preparation of the manuscript.

\section{Publisher's Note}

Springer Nature remains neutral regarding jurisdictional claims in published maps and institutional affiliations.

\section{References}

1. Gross JL, de Azevedo MJ, Silveiro SP, Canani LH, Caramori ML, Zelmanovitz T: Diabetic nephropathy: diagnosis, prevention, and treatment. Diabetes care 2005, 28(1):164-176.

2. Reutens AT: Epidemiology of diabetic kidney disease. The Medical clinics of North America 2013, 97(1):1-18.

3. Saran R, Li Y, Robinson B, Abbott KC, Agodoa LY, Ayanian J, Bragg-Gresham J, Balkrishnan R, Chen JL, Cope E et al: US Renal Data System 2015 Annual Data Report: Epidemiology of Kidney Disease in the United States. American journal of kidney diseases : the official journal of the National Kidney Foundation 2016, 67(3 Suppl 1):Svii, S1-305.

4. Alicic RZ, Rooney MT, Tuttle KR: Diabetic Kidney Disease: Challenges, Progress, and Possibilities. Clinical journal of the American Society of Nephrology : CJASN 2017, 12(12):2032-2045.

5. Gheith O, Farouk N, Nampoory N, Halim MA, Al-Otaibi T: Diabetic kidney disease: world wide difference of prevalence and risk factors. Journal of nephropharmacology 2016, 5(1):49-56.

6. Zhang G, Darshi M, Sharma K: The Warburg Effect in Diabetic Kidney Disease. Seminars in nephrology 2018, 38(2):111-120.

7. Shikata K, Makino H: Microinflammation in the pathogenesis of diabetic nephropathy. Journal of diabetes investigation 2013, 4(2):142-149.

8. Garcia-Garcia PM, Getino-Melian MA, Dominguez-Pimentel V, Navarro-Gonzalez JF: Inflammation in diabetic kidney disease. World journal of diabetes 2014, 5(4):431-443.

9. Bhat T, Teli S, Rijal J, Bhat H, Raza M, Khoueiry G, Meghani M, Akhtar M, Costantino T: Neutrophil to lymphocyte ratio and cardiovascular diseases: a review. Expert review of cardiovascular therapy 2013, 
11(1):55-59.

10. Dong $\mathrm{CH}$, Wang ZM, Chen SY: Neutrophil to lymphocyte ratio predict mortality and major adverse cardiac events in acute coronary syndrome: A systematic review and meta-analysis. Clinical biochemistry 2018, 52:131-136.

11. Wang Q, Ma J, Jiang Z, Ming L: Prognostic value of neutrophil-to-lymphocyte ratio and platelet-to-lymphocyte ratio in acute pulmonary embolism: a systematic review and meta-analysis. International angiology : a journal of the International Union of Angiology 2018, 37(1):4-11.

12. Afari ME, Bhat T: Neutrophil to lymphocyte ratio (NLR) and cardiovascular diseases: an update. Expert review of cardiovascular therapy 2016, 14(5):573-577.

13. Yao C, Liu X, Tang Z: Prognostic role of neutrophil-lymphocyte ratio and platelet-lymphocyte ratio for hospital mortality in patients with AECOPD. International journal of chronic obstructive pulmonary disease 2017, 12:2285-2290.

14. Angkananard T, Anothaisintawee T, McEvoy M, Attia J, Thakkinstian A: Neutrophil Lymphocyte Ratio and Cardiovascular Disease Risk: A Systematic Review and Meta-Analysis. BioMed research international 2018, 2018:2703518.

15. Yodying H, Matsuda A, Miyashita M, Matsumoto S, Sakurazawa N, Yamada M, Uchida E: Prognostic Significance of Neutrophil-to-Lymphocyte Ratio and Platelet-to-Lymphocyte Ratio in Oncologic Outcomes of Esophageal Cancer: A Systematic Review and Meta-analysis. Annals of surgical oncology 2016, 23(2):646654.

16. Zheng J, Cai J, Li H, Zeng K, He L, Fu H, Zhang J, Chen L, Yao J, Zhang Y et al: Neutrophil to Lymphocyte Ratio and Platelet to Lymphocyte Ratio as Prognostic Predictors for Hepatocellular Carcinoma Patients with Various Treatments: a Meta-Analysis and Systematic Review. Cellular physiology and biochemistry : international journal of experimental cellular physiology, biochemistry, and pharmacology 2017, 44(3):967-981.

17. Ohno R, Kawamoto R, Kanamoto M, Watanabe J, Fujii M, Ohtani H, Harada M, Kumagi T, Kawasaki H: Neutrophil to Lymphocyte Ratio is a Predictive Factor of Malignant Potential for Intraductal Papillary Mucinous Neoplasms of the pancreas. Biomarker insights 2019, 14:1177271919851505.

18. Azab B, Chainani V, Shah N, McGinn JT: Neutrophil-lymphocyte ratio as a predictor of major adverse cardiac events among diabetic population: a 4-year follow-up study. Angiology 2013, 64(6):456-465.

19. Kawamoto R, Ninomiya D, Kikuchi A, Akase T, Kasai Y, Kusunoki T, Ohtsuka N, Kumagi T: Association of neutrophil-to-lymphocyte ratio with early renal dysfunction and albuminuria among diabetic patients. International urology and nephrology 2019, 51(3):483-490.

20. Horio M, Imai E, Yasuda Y, Watanabe T, Matsuo S: Modification of the CKD epidemiology collaboration (CKDEPI) equation for Japanese: accuracy and use for population estimates. American journal of kidney diseases : the official journal of the National Kidney Foundation 2010, 56(1):32-38.

21. Tamhane UU, Aneja S, Montgomery D, Rogers EK, Eagle KA, Gurm HS: Association between admission neutrophil to lymphocyte ratio and outcomes in patients with acute coronary syndrome. The American journal of cardiology 2008, 102(6):653-657.

22. Paramanathan A, Saxena A, Morris DL: A systematic review and meta-analysis on the impact of pre-operative neutrophil lymphocyte ratio on long term outcomes after curative intent resection of solid tumours. Surgical oncology 2014, 23(1):31-39. 
23. Balta S, Celik T, Mikhailidis DP, Ozturk C, Demirkol S, Aparci M, lyisoy A: The Relation Between Atherosclerosis and the Neutrophil-Lymphocyte Ratio. Clinical and applied thrombosis/hemostasis : official journal of the International Academy of Clinical and Applied Thrombosis/Hemostasis 2016, 22(5):405-411.

24. Azab B, Daoud J, Naeem FB, Nasr R, Ross J, Ghimire P, Siddiqui A, Azzi N, Rihana N, Abdallah M et al: Neutrophil-to-lymphocyte ratio as a predictor of worsening renal function in diabetic patients (3-year follow-up study). Renal failure 2012, 34(5):571-576.

25. Ulu SM, Dogan M, Ahsen A, Altug A, Demir K, Acarturk G, Inan S: Neutrophil-to-lymphocyte ratio as a quick and reliable predictive marker to diagnose the severity of diabetic retinopathy. Diabetes technology \& therapeutics 2013, 15(11):942-947.

26. Afsar B: The relationship between neutrophil lymphocyte ratio with urinary protein and albumin excretion in newly diagnosed patients with type 2 diabetes. The American journal of the medical sciences 2014, 347(3):217-220.

27. Akbas EM, Demirtas L, Ozcicek A, Timuroglu A, Bakirci EM, Hamur H, Ozcicek F, Turkmen K: Association of epicardial adipose tissue, neutrophil-to-lymphocyte ratio and platelet-to-lymphocyte ratio with diabetic nephropathy. International journal of clinical and experimental medicine 2014, 7(7):1794-1801.

28. Ciray H, Aksoy AH, Ulu N, Cizmecioglu A, Gaipov A, Solak Y: Nephropathy, but not Angiographically Proven Retinopathy, is Associated with Neutrophil to Lymphocyte Ratio in Patients with Type 2 Diabetes. Experimental and clinical endocrinology \& diabetes : official journal, German Society of Endocrinology [and] German Diabetes Association 2015, 123(5):267-271.

29. Huang W, Huang J, Liu Q, Lin F, He Z, Zeng Z, He L: Neutrophil-lymphocyte ratio is a reliable predictive marker for early-stage diabetic nephropathy. Clinical endocrinology 2015, 82(2):229-233.

30. Youssef Moursy E: Relationship Between Neutrophil-Lymphocyte Ratio and Microvascular Complications in Egyptian Patients with Type 2 Diabetes. American Journal of Internal Medicine 2015, 3(6).

31. Kahraman C, Kahraman NK, Aras B, Cosgun S, Gulcan E: The relationship between neutrophil-to-lymphocyte ratio and albuminuria in type 2 diabetic patients: a pilot study. Archives of medical science : AMS2016, 12(3):571-575.

32. Xu T, Weng Z, Pei C, Yu S, Chen Y, Guo W, Wang X, Luo P, Sun J: The relationship between neutrophil-tolymphocyte ratio and diabetic peripheral neuropathy in Type 2 diabetes mellitus. Medicine 2017, 96(45):e8289.

33. Stringhini S, Batty GD, Bovet P, Shipley MJ, Marmot MG, Kumari M, Tabak AG, Kivimaki M: Association of lifecourse socioeconomic status with chronic inflammation and type 2 diabetes risk: the Whitehall II prospective cohort study. PLoS medicine 2013, 10(7):e1001479.

34. Devaraj S, Dasu MR, Jialal I: Diabetes is a proinflammatory state: a translational perspective. Expert review of endocrinology \& metabolism 2010, 5(1):19-28.

35. Buyukkaya E, Karakas MF, Karakas E, Akcay AB, Tanboga IH, Kurt M, Sen N: Correlation of neutrophil to lymphocyte ratio with the presence and severity of metabolic syndrome. Clinical and applied thrombosis/hemostasis : official journal of the International Academy of Clinical and Applied Thrombosis/Hemostasis 2014, 20(2):159-163.

36. Kaya H, Ertas F, Islamoglu Y, Kaya Z, Atilgan ZA, Cil H, Caliskan A, Aydin M, Oylumlu M, Soydinc MS: Association between neutrophil to lymphocyte ratio and severity of coronary artery disease. Clinical and applied thrombosis/hemostasis : official journal of the International Academy of Clinical and Applied Thrombosis/Hemostasis 2014, 20(1):50-54. 
37. Zhang J, Ren Q, Song Y, He M, Zeng Y, Liu Z, Xu J: Prognostic role of neutrophil-lymphocyte ratio in patients with acute ischemic stroke. Medicine 2017, 96(45):e8624.

38. Yang JJ, Hu ZG, Shi WX, Deng T, He SQ, Yuan SG: Prognostic significance of neutrophil to lymphocyte ratio in pancreatic cancer: a meta-analysis. World journal of gastroenterology 2015, 21(9):2807-2815.

\section{Table}

le 1. Baseline characteristics of subjects categorized by tertiles of baseline NLR.

\begin{tabular}{|c|c|c|c|c|}
\hline \multirow[b]{2}{*}{ əline Characteristics $\mathbf{N}=365$} & \multicolumn{4}{|c|}{ Tertiles of baseline NLR } \\
\hline & $\begin{array}{c}1^{\text {st. }}: 0.65-1.56 \\
\mathbf{N}=121\end{array}$ & $\begin{array}{c}2^{\text {nd }}: \begin{array}{c}1.57-2.33 \\
N\end{array}=123\end{array}$ & $\begin{array}{c}3^{\text {rd }}: 2.34-15.3 \\
\dot{N}=121\end{array}$ & $P$-value* \\
\hline (Male, \%) & 53.7 & 49.6 & 52.9 & 0.792 \\
\hline (years) & $73 \pm 11$ & $75 \pm 10$ & $77 \pm 11$ & 0.042 \\
\hline y mass index $\left(\mathrm{kg} / \mathrm{m}^{2}\right)$ & $25.2 \pm 3.8$ & $24.8 \pm 3.3$ & $23.3 \pm 3.8$ & $<0.001$ \\
\hline 2 diabetes (\%) & 95.0 & 100 & 97.5 & 0.044 \\
\hline od of diabetes (years) & $12.2 \pm 10.0$ & $11.2 \pm 8.5$ & $11.9 \pm 8.3$ & 0.647 \\
\hline king status † (\%) & $62.0 / 28.1 / 2.5 / 7.4$ & $69.1 / 26.0 / 3.3 / 1.6$ & $62.0 / 30.6 / 1.7 / 5.8$ & 0.404 \\
\hline y alcohol consumption $\ddagger(\%)$ & $66.1 / 6.6 / 19.0 / 8.3$ & $67.5 / 4.1 / 22.8 / 5.7$ & $69.4 / 5.0 / 15.7 / 9.9$ & 0.695 \\
\hline diovascular disease (\%) & 31.4 & 33.3 & 33.1 & 0.942 \\
\hline olic blood pressure (mmHg) & $144 \pm 20$ & $145 \pm 20$ & $140 \pm 19$ & 0.074 \\
\hline itolic blood pressure (mmHg) & $74 \pm 11$ & $72 \pm 14$ & $70 \pm 11$ & 0.030 \\
\hline hypertensive medication (\%) & 69.4 & 78.9 & 71.1 & 0.205 \\
\hline cholesterol (mg/dL) & $61 \pm 16$ & $56 \pm 15$ & $60 \pm 18$ & 0.075 \\
\hline -HDL cholesterol (mg/dL) & $132 \pm 31$ & $137 \pm 35$ & $124 \pm 32$ & 0.010 \\
\hline lipidemic medication (\%) & 36.4 & 32.5 & 30.6 & 0.623 \\
\hline loglobin A1c (\%) & $6.5(6.2-7.4)$ & $6.6(6.2-7.1)$ & $6.7(6.2-7.2)$ & 0.787 \\
\hline diabetic medication (\%) & 82.6 & 79.7 & 87.6 & 0.246 \\
\hline $\mathrm{Im}$ uric acid (mg/dL) & $5.5 \pm 1.3$ & $5.3 \pm 1.2$ & $5.1 \pm 1.3$ & 0.127 \\
\hline acid lowering medication (\%) & 9.1 & 7.3 & 5.8 & 0.617 \\
\hline stage \# (\%) & $76.0 / 20.7 / 3.3$ & $65.9 / 26.8 / 7.3$ & $66.9 / 23.1 / 9.9$ & 0.198 \\
\hline
\end{tabular}

גtrophil to lymphocyte ratio; HDL, high-density lipoprotein; UAE, urinary albumin excretion; eGFR, estimated glomerular filtration rate. $†$ Smokir ned as the number of cigarette packs per day multiplied by the number of years smoked (pack-year), and the participants were classified into ne , past smokers, light smokers ( $<20$ pack-year) and heavy smokers ( $\geq 20$ pack-year). $\ddagger$ Drinking status was measured using a Japanese liquor unit esponds to $22.9 \mathrm{~g}$ of ethanol (never-drinker, light-drinker ( $<1 \mathrm{unit} /$ day), moderate-drinker (1 to 2 unit/day)/heavy-drinker ( $\geq 2 \mathrm{unit} /$ day)). UAE st assified into A1 stage ( $<30 \mathrm{mg} / \mathrm{g}$ creatinine), A2 stage (30 to $300 \mathrm{mg} / \mathrm{g}$ creatinine, and A3 stage ( $\geq 300 \mathrm{mg} / \mathrm{g} \mathrm{creatinine}$ ). Data presented are me; I deviation. Data for hemoglobin A1c were skewed, are presented as median (interquartile range) values, and were log-transformed for analysis NOVA for continuous variables or the $\mathrm{c}^{2}$-test for categorical variables. The bold typeface indicates significance.

\section{1.5-year eGFR decline rate of subjects categorized by tertiles of ne NLR.}




\begin{tabular}{|c|c|c|c|c|}
\hline & \multicolumn{4}{|c|}{ Tertiles of baseline NLR } \\
\hline cteristics $\quad \mathrm{N}=365$ & $\begin{array}{c}1^{\text {st. }}: 0.65-1.56 \\
\mathbf{N}=121\end{array}$ & $\begin{array}{c}2^{\text {nd }}: 1.57-2.33 \\
N=123\end{array}$ & $\begin{array}{c}3^{\text {rd }}: 2.34-15.3 \\
\mathbf{N}=121\end{array}$ & $P$-value* \\
\hline $\begin{array}{l}\text { 1e eGFR } \\
\min / 1.73 \mathrm{~m}^{2} \text { ) }\end{array}$ & $67.6 \pm 12.9$ & $63.3 \pm 13.8$ & $61.9 \pm 15.3$ & 0.004 \\
\hline $\begin{array}{l}\text { after } 1.5 \text { years } \\
\text { le** } \\
\text { ar eGFR decline rate }\end{array}$ & $\begin{array}{l}65.1 \pm 12.3 \\
<0.001\end{array}$ & $\begin{array}{c}58.8 \pm 17.4 \\
<0.001\end{array}$ & $\begin{array}{c}58.8 \pm 19.0 \\
>0.001\end{array}$ & 0.007 \\
\hline $\begin{array}{l}, 0 \% \\
5 \%\end{array}$ & $\begin{array}{c}37(30.6 \%) \\
79(65.3 \%) \\
5(4.1 \%)\end{array}$ & $\begin{array}{l}32(26.0 \%) \\
67(54.5 \%) \\
24(19.5 \%)\end{array}$ & $\begin{array}{l}33(27.3 \%) \\
67(55.4 \%) \\
21(17.4 \%)\end{array}$ & 0.006 \\
\hline
\end{tabular}

Id typeface indicates significance. ${ }^{*} P$-value: ANOVA for continuous variables or the $\mathrm{c}^{2}$-test for rical variables. $* * P$-value: paired t- test.

\section{Relationships between baseline confounding factors and early}

2 decline rate.

\begin{tabular}{|c|c|c|c|}
\hline \multirow[b]{4}{*}{ line characteristics } & \multicolumn{3}{|c|}{ Rate of 1.5-year GFR decline < <15\% } \\
\hline & \multirow{3}{*}{$\begin{array}{l}\text { Simple correlation } \\
\text { r (p-value) }\end{array}$} & \multicolumn{2}{|c|}{ Multiple correlation $\S$} \\
\hline & & Model 1 & Model 2 \\
\hline & & $\beta$ ( $p$-value) & $\beta$ ( $p$-value) \\
\hline \multirow[t]{2}{*}{ er $($ Men $=0$, Women $=1)$} & $0.480(0.358)$ & $\square 0.036(0.601)$ & ----- \\
\hline & $0.168(0.001)$ & $0.124(0.050)$ & $0.156(0.002)$ \\
\hline \multirow{3}{*}{$\begin{array}{l}\text { mass index } \\
\text { of diabetes (type } 1=0 \text {, type } 2=1 \text { ) } \\
\text { d of diabetes (years) }\end{array}$} & $\square 0.016(0.762)$ & $\square 0.059(0.297)$ & --- \\
\hline & $0.063(0.227)$ & $0.007(0.897)$ & ------ \\
\hline & $0.013(0.798)$ & $\square 0.014(0.789)$ & ------ \\
\hline ring status & $\square 0.093(0.077)$ & $00.084(0.165)$ & ------ \\
\hline ring status & $\square 0.059(0.261)$ & $00.022(0.723)$ & ----- \\
\hline iovascular disease $(\mathrm{N}=0, \mathrm{Yes}=1)$ & $0.046(0.382)$ & $0.047(0.387)$ & ----- \\
\hline lic blood pressure & $0.122(0.019)$ & $0.075(0.214)$ & ----- \\
\hline olic blood pressure & $\square 0.019$ & $00.004(0.952)$ & ------ \\
\hline \multirow{2}{*}{$\begin{array}{l}\text { ypertensive medication }(\mathrm{N}=0, \text { Yes }=1) \\
\text { cholesterol }\end{array}$} & 0.116 & $0.038(0.496)$ & ----- \\
\hline & 00.112 & $\square 0.095(0.096)$ & ------ \\
\hline \multirow{3}{*}{$\begin{array}{l}\text { HDL cholesterol } \\
\text { ipidemic medication }(\text { No }=0, \text { Yes }=1 \text { ) } \\
\text { Jglobin A1c }\end{array}$} & $0.089(0.088)$ & $0.109(0.051)$ & $0.111(0.026)$ \\
\hline & $\square 0.027(0.612)$ & $\square 0.010(0.851)$ & ----- \\
\hline & $\square 0.064(0.224)$ & $00.141(0.013)$ & ------ \\
\hline iabetic medication $($ No $=0$, Yes $=1)$ & $0.029(0.581)$ & $0.112(0.044)$ & ------ \\
\hline \multirow{2}{*}{$\begin{array}{l}\mathrm{m} \text { uric acid } \\
\mathrm{tcid} \text { lowering medication }(\mathrm{No}=0, \text { Yes }=1)\end{array}$} & $0.042(0.429)$ & $0.010(0.847)$ & ------ \\
\hline & $0.009(0.861)$ & $00.034(0.509)$ & ----- \\
\hline \multirow{3}{*}{$\begin{array}{l}\text { stage } \\
\text { les of NLR }\end{array}$} & $0.280(<0.001)$ & $0.263(<0.001)$ & $0.258(<0.001)$ \\
\hline & $0.157(0.003)$ & $0.109(0.040)$ & $0.120(0.018)$ \\
\hline & & $0.164(<0.001)$ & $0.127(<0.001)$ \\
\hline
\end{tabular}

leutrophil to lymphocyte ratio; HDL, high-density lipoprotein; UAE, urinary albumin excretion. r, Pearson's correlatic ient. $\beta$, standard coefficient. $\mathrm{R}^{2}$, multiple coefficient of determination. Data for hemoglobin A1c, NLR, and UAE were $\mathrm{l}$ and log-transformed for analysis. § Adjusted for all confounding factors in Table 1 by multiple linear regression s (Model 1: forced entry method; Model 2: stepwise method). The numbers in bold indicate significance. 
Table 4. Non-adjusted and adjusted odds ratio (95\% CI) of tertiles of baseline NLR for 1.5-year early eGFR decline rate.

Tertiles of baseline NLR

\begin{tabular}{|c|c|c|c|c|c|c|}
\hline $\begin{array}{r}\text { 1.5-year eGFR decline rate }<015 \% \\
365\end{array}$ & $\begin{array}{c}1^{\text {st }}: 0.65- \\
1.56 \\
\mathrm{~N}=121 \\
\text { OR }(95 \% \\
\text { CI })\end{array}$ & $\begin{array}{c}2^{\text {nd }}: 1.57- \\
2.33 \\
N=123 \\
\text { OR }(95 \% \\
\text { CI })\end{array}$ & $\begin{array}{l}P \text { - } \\
\text { value }\end{array}$ & $\begin{array}{c}3^{\text {rd }}: 2.34- \\
15.3 \\
N=121 \\
\text { OR } \\
(95 \% \mathrm{CI})\end{array}$ & $P$-value & $P$-trend \\
\hline Non-adjusted & Preference & $\begin{array}{c}5.62 \\
(2.07- \\
15.3)\end{array}$ & 0.001 & $\begin{array}{c}4.87 \\
(1.77- \\
13.4)\end{array}$ & 0.002 & $<0.001$ \\
\hline Age-adjusted & Preference & $\begin{array}{c}5.41 \\
(1.98- \\
14.8)\end{array}$ & 0.001 & $\begin{array}{c}4.25 \\
(1.53- \\
11.8)\end{array}$ & 0.006 & 0.001 \\
\hline Multivariate-adjusted § & Preference & $\begin{array}{c}3.94 \\
(1.34- \\
11.6)\end{array}$ & 0.013 & $\begin{array}{c}3.93 \\
(1.26- \\
12.3)\end{array}$ & 0.018 & 0.003 \\
\hline
\end{tabular}

OR, odds ratio; CI, confidence interval. § Multivariate-adjusted for all confounding factors by multiple logistic regression analysis.

Table 5. Non-adjusted and adjusted eGFR after 1.5-year of subjects categorized by tertiles of baseline NLR.

\begin{tabular}{|c|c|c|c|c|c|}
\hline \multirow[b]{2}{*}{ eGFR after 1.5 years } & \multirow[b]{2}{*}{$\mathrm{N}=365$} & \multicolumn{4}{|c|}{ Tertiles of baseline NLR } \\
\hline & & $\begin{array}{c}1^{\text {st. }}: 0.65-1.56 \\
N=121 \\
\text { Mean }(95 \% \mathrm{CI})\end{array}$ & $\begin{array}{c}2^{\text {nd }}: 1.57-2.33 \\
\dot{N}=123 \\
\text { Mean }(95 \% \text { CI) }\end{array}$ & $\begin{array}{c}3^{\text {rd }}: 2.34-15.3 \\
N=121 \\
\text { Mean }(95 \% \mathrm{CI})\end{array}$ & $P$-value \\
\hline Non adjust & & $65.5(62.8-68.2)$ & $59.6(56.9-62.4)^{b}$ & $58.7(55.9-61.4)^{\mathrm{c}}$ & 0.037 \\
\hline Age-adjusted & & $64.2(61.8-66.6)$ & $59.7(57.3-62.0)^{\mathrm{a}}$ & $60.0(57.6-62.3)^{\mathrm{a}}$ & 0.024 \\
\hline Multivariate-adjuste & & $64.2(62.1-66.3)$ & $60.5(58.5-62.6)^{\mathrm{a}}$ & $59.1(57.0-61.2)^{\mathrm{C}}$ & 0.003 \\
\hline
\end{tabular}

CI, confidence interval. § Multivariate-adjusted for all baseline confounding factors including eGFR.

a: $p<0.05,{ }^{\mathrm{b}}: p<0.01,{ }^{\mathrm{c}}: \mathrm{p}<0.005$ versus $1^{\text {st }}$ tertile of baseline NLR.

\section{Figures}




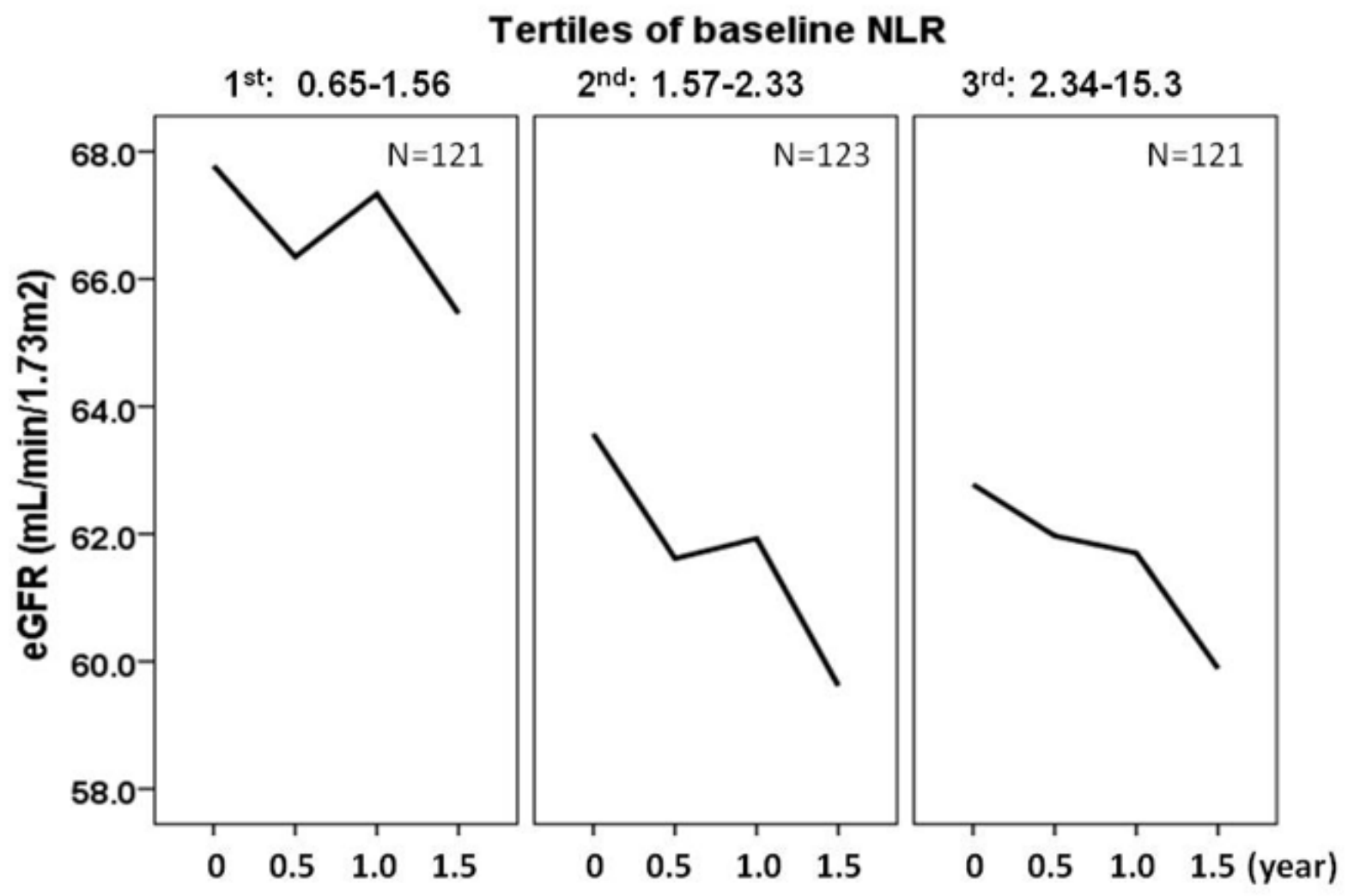

Figure 2

Change in eGFR of subjects categorized by tertile of baseline NLR. The change in mean eGFR during 1.5 years of the 1 st NLR tertile was more gradual compared with the 2nd and 3rd NLR tertiles. 